ELSEVIER

\title{
Review
}

\section{The Pivotal Role of Women in Cardiology Sections in Medical Organizations: From Leadership Training to Personal Enrichment}

\author{
Garima Sharma, MD, ${ }^{a}$ Sandra Lewis, MD, ${ }^{\mathrm{b}}$ Toniya Singh, MD, ${ }^{\mathrm{c}}$ Laxmi S. Mehta, MD, ${ }^{\mathrm{d}}$ \\ Jennifer Mieres, MD, ${ }^{\mathrm{e}}$ Athena Poppas, MD, ${ }^{\mathrm{f}}$ Robert Harrington, MD, ${ }^{\mathrm{g}}$ Ileana L. Piña, MD, MPH, \\ Annabelle Santos Volgman, MD, ${ }^{i}$ and Niti R. Aggarwal, $\mathrm{MD}^{\mathrm{j}}$ \\ ${ }^{a}$ Division of Cardiology, Ciccarone Center for the Prevention of Cardiovascular Disease, Johns Hopkins School of Medicine, Baltimore, Maryland, USA \\ ${ }^{b}$ Legacy Medical Group Cardiology, Portland, Oregon, USA \\ ${ }^{c}$ St Louis Heart and Vascular PC, St. Louis, Missouri, USA \\ ${ }^{d}$ Division of Cardiology, Department of Internal Medicine, The Ohio State University, Columbus, Ohio, USA \\ ${ }^{e}$ Division of Cardiology, Northwell Health, Zucker School of Medicine at Hofstra Northwell, Lake Success, New York, USA \\ ${ }^{f}$ Division of Cardiology, Warren Alpert Medical School of Brown University, Providence, Rhode Island, USA \\ ${ }^{g}$ Division of Cardiology, Stanford University, Palo Alto, California, USA \\ ${ }^{h}$ College of Medicine, Central Michigan University, Midlands, Michigan, USA \\ ${ }^{i}$ Division of Cardiology, Rush University, Chicago, Illinois, USA \\ ${ }^{j}$ Department of Cardiovascular Disease, Mayo Clinic, Rochester, Minnesota, USA
}

\begin{abstract}
Women in cardiology (WIC) sections have emerged as important leadership, career development, and advocacy forums for female cardiologists. Over the past 3 decades, they have grown from small groups to large sections within volunteer science organizations. In addition to providing a sense of community and promulgating the principles of diversity, equity, inclusion, and belonging, the WIC sections have contributed to improving workplace culture and dynamics by generating evidence-based and actionable data, fostering leadership by and scientific enrichment of women, developing task forces
\end{abstract}

\section{RÉSUMÉ}

Les sections WIC ("Women In Cardiology") des femmes en cardiologie sont devenues d'importants forums de leadership, de développement de carrière et de défense des intérêts des femmes cardiologues. Au cours des trois dernières décennies, leur potentiel est passé de petits groupes à de grandes sections au sein d'organisations scientifiques bénévoles. En plus de donner un sentiment d'appartenance à une communauté et de promouvoir les principes de diversité, d'équité, d'inclusion et d'appartenance, les sections WIC ont contribué à améliorer la culture et la dynamique du milieu de travail en proposant
The community of women in cardiology (WIC), nurtured through professional societies, has become a home to support and develop the careers of female cardiologists. The history of WIC prior to the 1990 s was a history of individuals. Pioneers,

Received for publication June 17, 2021. Accepted July 27, 2021.

Ethics Statement: The research reported has adhered to the relevant ethical guidelines.

Corresponding author: Dr Garima Sharma, Assistant Professor of Medicine, Division of Cardiology, Johns Hopkins University School of Medicine, 565C Carnegie, $600 \mathrm{~N}$ Wolf St, Baltimore, Maryland 21287, USA. Tel.: +1443-442-2017; fax: +1-443-442-2018.

E-mail: gsharma8@jhmi.edu

See page S100 for disclosure information. such as Dr Helen Taussig, the founder of pediatric cardiology, and Dr Myra Adele Logan, the first woman surgeon to perform bypass surgery, essentially stood alone in terms of their gender among their male colleagues. ${ }^{1}$ As more women entered the field of medicine through the 1970s, cardiology began to see a small but steady increase in women. This increase in numbers was bolstered by the leadership presence of female cardiologists. Election of Dr Jacqueline Noonan as the first female governor of a chapter of the American College of Cardiology (ACC) in Kentucky in 1977 was the start of representation of female cardiologists in leadership positions in the field (Fig. 1). ${ }^{2}$

To provide a professional home and a stronger voice to the growing numbers of WIC, both the American Heart 
and health policy documents targeted toward reduction of burnout and bias in medicine, and providing a platform to voice the unique challenges and opportunities of female cardiologists. The future holds great promise, as the WIC sections continue to play a pivotal role by being intentional, transparent, iterative, and sustainable, and working with important stakeholders, including men, to share data, best practices, and strategies to create and maintain a culture of equity and achieve its core principles.
Association (AHA) and the ACC have recognized the need for formal sections of women. Charged with the mission of advancing the clinical and research careers of women cardiologists, the AHA created a task force within the Council on Clinical Cardiology in 1992 that has now become a committee under the larger Council Operations Committee. ${ }^{3}$ Following the AHA, in 1994, the ACC organized a WIC committee, and both professional organizations formalized their sections by 1998. In 2001, for the first time, there was an inaugural joint meeting of female cardiologists represented by the ACC, the AHA, the European Society of Cardiology, the Association of Black Cardiologists, the Heart Rhythm Society, the American Society of Nuclear Cardiology, and the Society of Cardiac Angiography and Intervention. $^{3}$

By 1996, female cardiologists represented about $5 \%$ of cardiovascular physicians, but the number of women in cardiology continued to lag behind the number in other medical specialties. ${ }^{4}$ Presently, although women continue to be underrepresented in cardiology, they have come a long way and hold an increasingly visible role in governance, education, and advocacy. The ACC WIC section has had a long and fruitful journey from its inception in the early 1990 s to its impact 18 years later at the 35th Bethesda Conference, held yearly from 2003 to 2021, and it maintains a pivotal role in the advancement of female cardiologists. ${ }^{5}$ This article describes the important professional and personal challenges faced by female cardiologists and the pivotal role of the WIC sections in advancing the mission of diversity, equity, inclusion, and belonging within the field of cardiology.

\section{Challenges to Achieving Gender Equity in Cardiology}

Several task forces and publications have previously identified practices, policies, and beliefs that sustain gender inequities within our field. ${ }^{6}$ These include a wide array of challenges experienced disproportionately by female cardiologists, especially those of racial and ethnic minorities.

Even though women comprise $51 \%$ of medical school graduates, and $43 \%$ of residents in internal medicine, only $21 \%$ of cardiology fellows are women. ${ }^{7,8}$ Women are even des données factuelles et exploitables, en encourageant le leadership et l'enrichissement scientifique des femmes, en créant des groupes de travail et des documents de politique de santé visant à réduire l'épuisement professionnel et les préjugés en médecine, et en offrant une plateforme pour exprimer les défis et les opportunités uniques des femmes cardiologues. L'avenir semble très prometteur puisque les sections WIC continuent de jouer un rôle central en étant conscientes, transparentes, itératives et durables et en travaillant avec des parties prenantes importantes, y compris masculines, pour partager des données, des meilleures pratiques et des stratégies afin de créer et d'en maintenir la culture et de concrétiser ses principes fondamentaux.

more underrepresented in procedural subspecialty fellowships, with fewer than $14 \%$ of these going to women. Among practicing cardiologists, only $13 \%$ are women, and only $8 \%$ of underrepresented ethnic and racial minority groups are women. Additionally, women are underrepresented in leadership positions and receive fewer academic promotions than men. ${ }^{9}, 10$ Even now in 2021, women physicians comprise only $21 \%$ of full professors, $15 \%$ of department chairs, and $16 \%$ of medical school deans in the United States. ${ }^{11}$ Additionally, there is suboptimal visibility of women in scholarly activity, with only $12 \%$ of the editorial boards of major journals being women, and $88 \%$ being men. ${ }^{12,13}$ Measures of academic productivity, such as publication and grand-round speakers, also reflect inequity for women, as compared to men. ${ }^{14-16}$ As more women become increasingly visible as members and leaders in the cardiology field, they often face pressure to conform to the existing male-dominated organizational leadership structures, with an emphasis on "masculine" characteristics, and "male" leadership styles can be seen as necessary to demonstrate success. ${ }^{17}$ Women can also become victims of the "conventional" consequences of gender discrimination and social identity threat as manifested in the "queen bee" phenomenon. ${ }^{18}$ This phenomenon is seen when women leaders distance themselves from junior women, thereby "legitimizing" and tacitly sustaining gender inequality in their organization. ${ }^{18,19}$

This situation is further compounded by gender inequity in compensation and promotion. ACC WIC leadership group publications highlight the fact that women in cardiology are paid less than men for performing similar clinical roles. ${ }^{20}$ Indeed, according to data from the Association of American Medical Colleges from 2017, female cardiologists were paid 78 cents for every dollar paid to men. ${ }^{20}$ Even after adjusting for the different job productivity characteristics, female physicians made $\$ 32,000$ less annually compared to men. ${ }^{21}$ Meticulous care and attention to critical issues, such as fairness, equity, and transparency, and to inequities in compensation and promotion are necessary to achieve gender parity. Discrimination and harassment are behaviors that contribute to workplace toxicity, ${ }^{22-24}$ and they affect workplace environments and productivity. ${ }^{23,24} \mathrm{~A}$ recent survey from the ACC Women in Cardiology Section of about 6000 cardiologists, on the global prevalence of hostility, harassment, and 


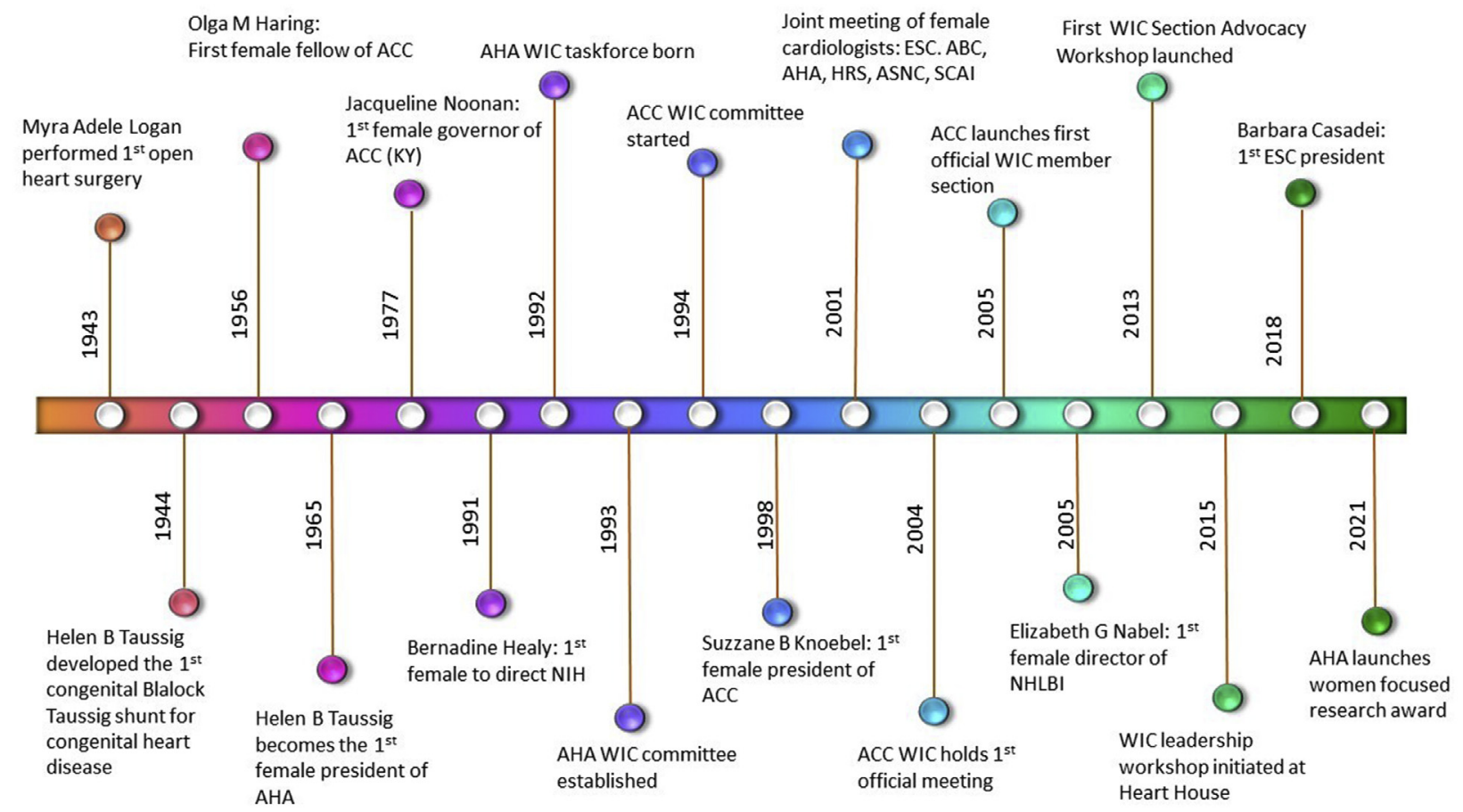

Figure 1. Timeline of the important events relating to women-in-cardiology sections and achievements of women cardiologists. ABC, Association of Black Cardiologists; ACC, American College of Cardiology; AHA, American Heart Association; ASNC, American Society of Nuclear Cardiology; ESC, European Society of Cardiology; HRS, Heart Rhythm Society; NHLBI, National Heart, Lung, and Blood Institute; NIH, National Institutes of Health; SCAl, Society for Cardiovascular Angiography; WIC, Women in Cardiology.

discrimination in cardiology, found that the overall prevalence of a hostile work environment was $44 \%$ (no region was immune), but $67 \%$ of women reported experiencing some sort of workplace toxicity. Furthermore, in 2018, the seminal National Academy of Sciences, Engineering, and Medicine (NASEM) study "Sexual Harassment of Women: Climate, Culture, and Consequences in Academic Sciences, Engineering, and Medicine," found that half of all women in medical school have experienced some form of sexual harassment from both women and men. ${ }^{25}$ ACC WIC has conducted 3 professional-life surveys to assess gender-based cardiologists' professional advancement and satisfaction, and it has highlighted the gender- based disparity in workplace environment, and the need for improved diversity and inclusion. ${ }^{4,24,26}$

Women experience burnout and professional exhaustion more than men. ${ }^{27,28}$ Previous data from the ACC Professional Life Survey reported that less than $25 \%$ of cardiologists enjoyed their work, nearly $50 \%$ were stressed, and just over $25 \%$ were burned out. ${ }^{28}$ Furthermore, the prevalence of burnout among cardiologists and cardiology fellows in training was higher for women than men $(31 \%$ vs $24 \%){ }^{28}$ Some women experience "imposter syndrome," a feeling of being inadequate or fraudulent despite having the qualifications, accolades, and attributes to succeed, and may have depression, anxiety, low self-esteem, somatic symptoms, and social dysfunction. ${ }^{29-31}$ Doubting achievements and suitability for various opportunities can lead to missed progress in leadership, creating a vicious cycle of negative self-attribution, lack of self-confidence, and even self-sabotage, which can negatively impact mental health and wellness ${ }^{32,33}$ and be an important impediment to success. ${ }^{29}$
Lastly, women juggle pregnancy, parenting, and caregiving responsibilities. Family planning decisions often occur early in a women's career and include concerns about radiation exposure, breastfeeding in the workplace, and childcare responsibilities. ${ }^{34}$ According to a survey conducted by the ACC WIC section in 2015, domestic responsibilities often hindered female cardiologists from traveling for professional advancements and required them to cut back on professional commitments. ${ }^{24}$ Furthermore, women were more likely to be single ( $14 \%$ vs $5 \%)$ and not have children ( $28 \%$ vs $13 \%)$. These contemporary challenges underscore the need for improved women-friendly workplace policies, an appreciation of these challenges by male colleagues and partners who can assist, and support-system WIC community members to strategize and commiserate. WIC groups are strenghtened by men allies.

\section{The Role of Women in Cardiology Groups and a Roadmap to Gender Equity}

Given the challenges of underrepresentation of female cardiologists, and the additional burdens borne by them, the WIC groups were created to promulgate the principles of diversity, equity, inclusion, and belonging. Over the past 3 decades, the ACC and AHA WIC groups have improved the visibility and representation of female cardiologists through advocacy, leadership opportunities, and kinship and camaraderie (Table 1; Fig. 2). They have provided an avenue for women to enrich their lives both professionally and personally. Below is a list of initiatives that shaped the mission, vision, and core values of the WIC sections of the AHA and ACC. 


\section{Data generation to assess gender inequity}

With the overarching goal of promoting professional development and improving recruitment and retention of women in cardiology, over the past 3 decades, the WIC groups have been instrumental in providing metrics and measurable impact to promote gender equity in compensation, opportunity, and work-life balance. ${ }^{13}$ The ACC WIC group has commissioned 3 professional-life surveys to assess gender-based cardiologists' professional advancement and satisfaction, including but not limited to evidence of burnout, discrimination, harassment, mental disorders and illness, parity in rank and leadership, gender equity in compensation, and parental leave policies during fellowship training and in practice. ${ }^{4,6,24,26,34-36}$ Often partnering with external organizations such as MedAxiom, the WIC groups may collect, benchmark, and report data on gender disparities in compensation and academic promotion, thereby creating transparency. These data serve as important metrics to elucidate gender-based barriers and inequities, and they often serve as the basis for workforce policy changes by medical organizations, institutions, and public health agencies.

\section{Training and education}

Training to improve diversity and inclusion. With data from more than 3 decades, there is evidence that the role of WIC groups is even more important now in moving from data collection to dissemination and implementation of strategies targeted toward driving sustainable change in the culture of cardiology globally. The discussion on reducing bias, the creation of diversity and inclusion task forces that are mission-centric, and data dashboards with a particular focus on diversity and equitable workplaces are a start. Other implementation strategies include efforts by WIC sections to educate their members and others to recognize and reduce implicit bias, increase cultural competency, promote alliances, and mitigate harassment by promoting a culture of inclusivity.

Leadership training. Emerging data show that education and training can help women be more prepared for leadership roles, ${ }^{19,37}$ by including a formal approach to leadership development. In particular, the ACC WIC section instituted an annual leadership workshop to improve leadership skills such as conflict resolution, crisis management, driving organizational change, effective mentoring and sponsorship, strategic finance, and resource management. Through similar workshops and webinars, the WIC has also delivered evidence-based strategies for improving career development, such as negotiations, crucial conversations, persuasive public speaking, and media interviewing. These enrichment sessions provide yearlong resources for female cardiologists. ${ }^{37}$

Training to empower women. Through publication of peer-reviewed articles, provision of in-person and web-based conferences, and use of journal clubs, the WIC groups provide a safe and confidential forum to discuss and validate gender-based challenges and develop potential solutions to overcome them. WIC sections have played a pivotal role in creating self-awareness and mitigating the psychological impact of imposter syndrome. These educational and supportive conversations are designed to empower female cardiologists to speak up and have a "seat at the table," and they offer methods to improve negotiation skill, thereby promoting compensation equity. Additionally, to combat sexual harassment, the ACC Leadership Forum launched a special session in 2018 entitled "Me Too, But Now What?"37 The session was aimed at educating the incoming ACC leadership about how to reduce gender bias and provide a safe and accountable work climate in the field of cardiology. ${ }^{38}$

Training for research. With the goal of reducing gender disparity in clinical trials, research and publications, the ACC launched the program "Clinical Trials Research: Upping Your Game." ${ }^{39}$ This program is designed to teach its participants about clinical trial methodology, and to offer an opportunity to network with nationally recognized clinical trialists, investigators, and industry leaders and develop a personal career pathway. The program is intended to increase the representation of women and ethnic minorities traditionally underrepresented in cardiology.

\section{Advocacy}

Beyond data collection and training of the workforce, in order to implement change, WIC groups must be

Table1. Challenges faced by women cardiologists and potential solutions that can be addressed by women-in-cardiology groups

\begin{tabular}{|c|c|}
\hline Challenges & Potential solutions by women-in-cardiology groups \\
\hline $\begin{array}{l}\text { Underrepresentation in leadership, } \\
\text { scholarship, compensation, and } \\
\text { promotion, on editorial boards, and } \\
\text { in cardiology subspecialties }\end{array}$ & $\begin{array}{l}\text { - Collecting, compiling, and comparing benchmarking data on gender equity in cardiology } \\
\text { - Dissemination of data through publications focused on achieving gender equity } \\
\text { - Developing health policy statements aimed at achieving parity and opportunity equity in compensation and } \\
\text { promotion } \\
\text { - Identification of barriers in recruitment, retention, and career advancement }\end{array}$ \\
\hline $\begin{array}{l}\text { Under-mentoring and under- } \\
\text { sponsorship }\end{array}$ & $\begin{array}{l}\text { - Developing mentorship and sponsorship programs for women in all stages of their professional careers } \\
\text { - Professional development and executive leadership courses } \\
\text { - Research training aimed at grant writing, clinical trial leadership, etc. }\end{array}$ \\
\hline $\begin{array}{l}\text { Harassment, bias, bullying, and } \\
\text { discrimination }\end{array}$ & $\begin{array}{l}\text { - Promoting a culture of inclusivity by bias-reduction training } \\
\text { - Promotion of ally relationship with bystanders } \\
\text { - Developing zero-tolerance procedures to mitigate harassment and victim shaming and blaming }\end{array}$ \\
\hline $\begin{array}{l}\text { Challenges with work-life integration } \\
\text { and burnout }\end{array}$ & $\begin{array}{l}\text { - Improving sense of community and camaraderie by means of networking and professional groups that are safe } \\
\text { spaces to express concerns and discuss solutions }\end{array}$ \\
\hline
\end{tabular}




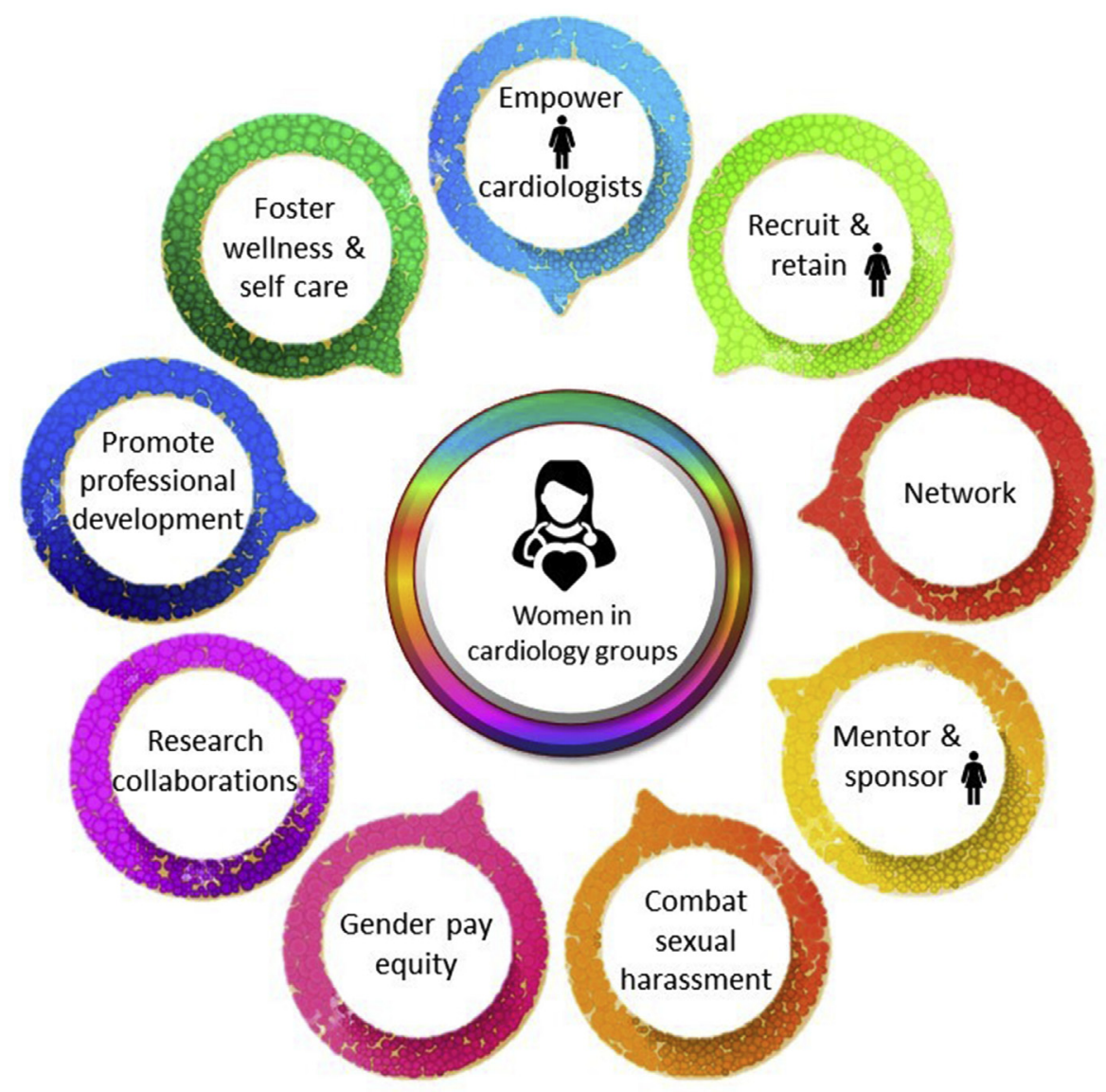

Figure 2. The role of women-in-cardiology sections in medical organizations-from career development to professional enrichment.

powerful advocates for women facing women-specific challenges. The WIC groups can advocate for additional resources and female-friendly policies through legislation, healthcare systems, and their own medical societies. Increased funding from both government and industry sources that is especially focused on female researchers, who are currently underrepresented in cardiology, may improve equity in clinical trial leadership and help bridge the gender divide. To address gender disparity in compensation, WIC leaders steered creation of a recent ACC Health Policy Statement on compensation and opportunity equity. ${ }^{40,41}$ That policy statement put forward the following ideas: compensation plans should be based on principles aligned with the overall strategic goals of the organization; compensation should be equitable and fair, blind to sex, race, and ethnicity; metrics should be objectively determined; and all work (beyond billable clinical efforts) should be valued and transparency should be maintained in the creation and implementation of the compensation model. ${ }^{41}$ These leaders advocated for a transparent salary scale based on rank and years in service, to ensure that compensation is based purely on merit and effort, rather than gender. WIC groups have often also advocated for changes in work environments to support working mothers, including the presence of lactation rooms and onsite childcare support during medical conferences, and parental leave during training.

\section{Networking}

Formal mentoring. Both the ACC and AHA WIC sections have had formal and informal mentorship programs as a member value and benefit. The AHA's "Mentoring for Professionals" program, supported by the corresponding WIC section, provides a unique opportunity for new and early career members to connect with and benefit from the experience of distinguished members. ${ }^{42}$ The main goal of these programs is to set goals, create an action plan, and create a relationship with a focus on career advancement. WIC sections have strongly supported these mentorship and sponsorship programs to enhance professional development for women physician-scientists. Mentoring early in a woman's career is important to address the contemporary challenges of gender inequity in recruitment and retention. Additionally, the presence of consistent mentoring and sponsorship by WIC groups can improve the visibility of younger women engaged in academic pursuits, and help build their academic dossier for promotion. Overall, the WIC section has provided several micro-mentoring opportunities and fostered long-lasting relationships that extend beyond scientific sessions.

Improved visibility through sponsorship. A critical role that the WIC group can play is providing its members with access to leadership opportunities within medical organizations. Most institutions require demonstration of a regional or 
national reputation as a prerequisiste for promotion to associate professor and professor, respectively. Leadership in an ACC or AHA statewide initiative or chapter can help develop cardiologists develop a regional reputation, and participation on editorial boards, writing committees, and grant review sections can provide credible evidence of a national reputation within a field. WIC leaders can help guarantee that women are considered for these positions and advocate for their inclusion. Additionally, individual WIC leaders can extend invitations for lectureships, visiting professorships, and other activities at their home institutions to female cardiologists and scientists.

Peer-to-peer mentoring. Furthermore, social networking and solution-driven conversations can help foster inclusion, a sense of belonging, and professional fulfillment, and ultimately, they can reduce burnout. These networks may help with building self-esteem, self-confidence, self-advocacy for writing groups, and self-management skills that can help identify coping strategies to mitigate the effect of imposter syndrome. Having a support network of women who face similar challenges may foster self-reflection, promote reframing, and align actions within a "big picture" context, thereby reducing feelings of insecurity. ${ }^{30,38}$ This supportive network is important across the span of a woman's career, as the complexity of issues women face varies throughout their career stages.

\section{Building a WIC community through social media}

Use of social media has emerged as an essential channel for networking, mentoring, and sponsorship, and dissemination of leadership and career life skills and gender advocacy at a global scale. Several WIC private groups have formed that discuss and validate the challenges faced by female cardiologists, and serve as a means to virtually collaborate, uplift, and support each other beyond the constraints of their home institutions. For example, the WIC Facebook group, a private group created in 2014, has grown to include more than 1500 cardiologists and other women working in the field. ${ }^{43}$ The Women in Cardiology Global Facebook group ${ }^{44}$ routinely amplifies webinars and publications on gender-parity issues. Similarly, on Twitter, several hashtags, including \#ACCWIC, \#AHAWIC, \#WomeninCardiology, and \#ilooklikeacardiologist, have emerged that help organize and curate content pertaining to gender inequity, and they have resulted in a robust virtual global community of female cardiologists. This network is highlighted by the consequential generation of $>$ 48,000 tweets and 266 million impressions, and acquisition of 12,485 users over a 3-year timeframe. ${ }^{45}$ Members often form real-life connections when they meet up at in-person cardiology conferences. These virtual networks serve as a means for virtual community building, professional development, and gender advocacy.

\section{Conclusion}

Women and other historically underrepresented groups face unique challenges in cardiology and other professions. As outlined above, women cardiologists face internal and external challenges - the imposter syndrome that can hold a woman back, direct discrimination and harassment, burnout and depression, and undermentoring and sponsorship. Although progress has been made in gender equity in the field of cardiology, with women making strides in leadership roles and professional achievement, many women are still struggling to truly thrive and find a pathway for desired career advancement.

We all need a home- a professional environment in which one feels safe and supported. The AHA, ACC, and other professional societies have supported women physicians through specific cardiology committees and actions. Networking fosters inclusion, belonging, and satisfaction. Societies must promote transparent compensation, flexible and fair promotion requirements, and ample leadership opportunities in academia and practice. We can "pay it forward" with role models and mentors, and by sponsoring our next generation.

Our solutions must be intentional, transparent, iterative, and sustainable. They require working with men, women, and non-binary individuals to share data, best practices, and strategies to create and maintain a culture that achieves the core mission.

\section{Funding Sources}

G.S. is supported by the Blumenthal Scholarship in Preventive Cardiology.

The other authors have no funding sources to declare.

\section{Disclosures}

The authors have no conflicts of interest to disclose.

\section{References}

1. Vosloo SM. Realities and challenges for female cardiothoracic surgeons: an African perspective. J Thorac Dis 2021;13:448-55.

2. Attenhofer Jost C, Zimmerli Vögtli M, Grünenfelder K, et al. Women in cardiology: past, present and future. Cardiovasc Med 2019;22:w02022.

3. Wenger NK. Women in cardiology: the US experience. Heart 2005;91: 277-9.

4. Limacher MC, Zaher CA, Walsh MN, et al. The ACC professional life survey: career decisions of women and men in cardiology: a report of the Committee on Women in Cardiology. American College of Cardiology. J Am Coll Cardiol 1998;32:827-35.

5. Warnes CA, Fedson SE, Foster E, et al. Working group 2: how to encourage more women to choose a career in cardiology. J Am Coll Cardiol 2004;44:238-41.

6. Sharma G, Sarma AA, Walsh MN, et al. 10 recommendations to enhance recruitment, retention, and career advancement of women cardiologists. J Am Coll Cardiol 2019;74:1839-42.

7. Mehta LS, Fisher K, Rzeszut AK, et al. Current demographic status of cardiologists in the United States. JAMA Cardiol 2019;4:1029-33.

8. Khan MS, Mahmood S, Khan SU, et al. Women training in cardiology and its subspecialties in the United States: a decade of little progress in representation. Circulation 2020;18:609-11.

9. Walsh MN. Women as leaders in cardiovascular medicine. Clin Cardiol 2018;41:269-73.

10. Mehran R. Women's voices in cardiology: an uncomfortable silence. JAMA Cardiol 2018;3:676-7. 
11. Butkus R, Serchen J, Moyer DV, et al. Achieving gender equity in physician compensation and career advancement: a position paper of the American College of Physicians. Ann Intern Med 2018;168:721-3.

12. Balasubramanian S, Saberi S, Yu S, et al. Women representation among cardiology journal editorial boards. Circulation 2020;141:603-5.

13. Ouyang D, Sing D, Shah S, et al. Sex disparities in authorship order of cardiology scientific publications. Circ Cardiovasc Qual Outcomes 2018;11:e005040.

14. Reza N, Tahhan AS, Mahmud N, et al. Representation of women authors in international heart failure guidelines and contemporary clinical trials. Circ Heart Fail 2020:13:e066605.

15. Mehran R, Kumar A, Bansal A, et al. Gender and disparity in first authorship in cardiology randomized clinical trials. JAMA Netw Open 2021; $4: e 211043$.

16. Files JA, Mayer AP, Ko MG, et al. Speaker introductions at internal medicine grand rounds: forms of address reveal gender bias. J Womens Health (Larchmt 2017;26:413-9.

17. Helfat CE, Harris D, Wolfson PJ. The pipeline to the top: women and men in the top executive ranks of U.S. corporations. Acad Manag Perspect 2006;20:42-64.

18. Derks B, Van Laar C, Ellemers N. The queen bee phenomenon: why women leaders distance themselves from junior women. Leadersh Q 2016;27:456-69.

19. Jogulu UD, Wood GJ. The role of leadership theory in raising the profile of women in management. Equal Oppor Int 2006;25:236-50.

20. Association of American Medical Colleges. FY 2017 median compensation in cents on the dollar for women in medicine specialty. Available at: https://www.aamc.org/media/10996/download. Accessed June 17, 2021.

21. Jagsi R, Biga C, Poppas A, et al. Work activities and compensation of male and female cardiologists. J Am Coll Cardiol 2016;67:529-41.

22. Quine L. Workplace bullying, psychological distress, and job satisfaction in junior doctors. Camb Q Healthc Ethics 2003;12:91-101.

23. Dzau VJ, Johnson PA. Ending sexual harassment in academic medicine. N Engl J Med 2018;379:1589-91.

24. Lewis SJ, Mehta LS, Douglas PS, et al. Changes in the professional lives of cardiologists over 2 decades. J Am Coll Cardiol 2017;69:452-62.

25. Johnson PA, Widnall SE, Benya FF, eds. Sexual Harassment of Women: Climate, Culture, and Consequences in Academic Sciences, Engineering, and Medicine. Washington, DC: National Academies Press, 2018.

26. Poppas A, Cummings J, Dorbala S, et al. Survey results: a decade of change in professional life in cardiology: a 2008 report of the ACC Women in Cardiology Council. J Am Coll Cardiol 2008;52:2215-26.

27. Maslach C, Jackson SE, Leiter MP. Maslach Burnout Inventory Manual. Palo Alto: Mind Garden, 2018.

28. Mehta LS, Lewis SJ, Duvernoy CS, et al. Burnout and career satisfaction among U.S. cardiologists. J Am Coll Cardiol 2019;73:3345-8.

29. Clance PR, Imes SA. The imposter phenomenon in high achieving women: dynamics and therapeutic intervention. Psychother Theory Res Pract $1978 ; 15: 241-7$.
30. Mullangi S, Jagsi R. Imposter syndrome: Treat the cause, not the symptom. JAMA 2019;322:403-4.

31. Cader FA, Gupta A, Han JK, et al. How feeling like an imposter can impede your success. JACC Case Rep 2021;3:347-9.

32. Bravata DM, Watts SA, Keefer AL, et al. Prevalence, predictors, and treatment of impostor syndrome: a systematic review. J Gen Intern Med 2020;35:1252-75.

33. Ladonna KA, Ginsburg S, Watling C. "Rising to the Level of Your Incompetence": What physicians' self-assessment of their performance reveals about the imposter syndrome in medicine. Acad Med 2018;93: 763-8.

34. Douglas PS, Rzeszut AK, Noel Bairey Merz C, et al. Career preferences and perceptions of cardiology among US internal medicine trainees factors influencing cardiology career choice. JAMA Cardiol 2018;3:682-91.

35. Sharma G, Douglas PS, Hayes SN, et al. Global prevalence and impact of hostility, discrimination, and harassment in the cardiology workplace. J Am Coll Cardiol 2021;77:2398-409.

36. Sarma AA, Nkonde-Price C, Gulati M, et al. Cardiovascular medicine and society:the pregnant cardiologist. J Am Coll Cardiol 2017;69: $92-101$.

37. American College of Cardiology. 2020 women in cardiology leadership workshop. Available at: https://www.acc.org/Education-and-Meetings/ Meetings/Features/2020/OnDemand-2020-WIC-Leadership-Workshop. Accessed June 8, 2021.

38. Kamirisa KP, Volgman AS, Parwani P, Lundberg GP. Advocacy to end sexual harassment: voices from women in cardiology. Available at: https://www.jacc.org/doi/pdf/10.1016/j.jaccas.2021.04.029. Accessed June17, 2021.

39. American College of Cardiology. Clinical trials research: upping your game. Available at: https://www.acc.org/CTR2022. Accessed June 17, 2021.

40. Douglas PS, Williams KA Sr, Walsh MN. Diversity matters. J Am Coll Cardiol 2017;70:1525-9.

41. Douglas PS, Biga C, Burns KM, et al. 2019 ACC health policy statement on cardiologist compensation and opportunity equity. J Am Coll Cardiol 2019;74:1947-65.

42. American Heart Association. Mentoring for professionals. Available at: https://professional.heart.org/en/partners/mentoring-for-professionals. Accessed June 2, 2021.

43. Women in Cardiology. Facebook group. Available at: https://www. facebook.com/groups/745868888796666. Accessed June 17, 2021.

44. Women in Cardiology-Global-Early Career. Facebook group. Available at: https://www.facebook.com/Global-Women-in-Cardiology-EarlyCareer-129697691938830/. Accessed June 17, 2021.

45. Chandra NV, Hsiao R, Shapiro H, et al. Women in cardiology twitter network: an analysis of a global professional virtual community from 2016 to 2019. J Am Heart Assoc 2021;10:e019321. 